Access to this work was provided by the University of Maryland, Baltimore County (UMBC)

ScholarWorks@UMBC digital repository on the Maryland Shared Open Access (MD-SOAR) platform.

Please provide feedback

Please support the ScholarWorks@UMBC repository by emailing scholarworks-group@umbc.edu and telling us what having access to this work means to you and why it's important to you. Thank you. 


\title{
From Cells-on-a-chip to Organs-on-a-chip: Scaffolding Materials for 3D Cell Culture in Microfluidics
}

John A. Terrell, Curtis G. Jones, Giraso Keza Monia Kabandana, and Chengpeng Chen*

\author{
${ }^{*}$ corresponding to \\ Dr. Chengpeng Chen \\ Department of Chemistry and Biochemistry \\ University of Maryland Baltimore County \\ MD, USA, 21250 \\ cpchen@umbc.edu \\ $+1-4104553053$
}




\section{INTRODUCTION}

There are immediate needs to develop reliable tissue models for pre-clinical research. It costs $\$ 2.5$ billion and $10-15$ years on average to bring a drug to market ${ }^{1}$. To decrease the cost of drug development, it is critical to improve the predictive power of pre-clinical screenings for excluding ineffective/toxic candidates as early as possible (so called "fail early, fail cheaply") ${ }^{2}$. Currently, the typical workflow in pre-clinical tests is to screen drug candidates on statically cultured cells followed by animal (e.g. rodent) experiments. However, both models have inherent limitations. Although static cell culture experiments are simple to conduct, this method only applies a monolayer of cells in a container. For most studies this does not adequately recreate the tissue/organ-level cellular complexity and 3D microenvironments (e.g. extracellular matrix, ECM), making many results fail to be extrapolated to subsequent clinical trials ${ }^{3}$. Animal models provide a platform for investigations on the organ and system levels. However, these expensive, time-consuming, and low-throughput experiments may not reflect human physiology; evidence shows that small genomic differences between species can lead to major aggregated physiological variances ${ }^{4}$. Indeed, based on these models, only $1 \%$ of the efficacy and toxicity results succeeds in subsequent clinical studies ${ }^{5}$.

In the past two decades, advances in microfluidic technologies have provided a new platform for culturing cells in a more physiologically relevant manner ${ }^{6}$. Microfluidics are devices with $\mu \mathrm{m}$-scale fluidic channels for controlled flow in small volumes $(\mu \mathrm{L})^{7}$. These cell-laden microfluidic devices are often referred to as organs-on-a-chip ${ }^{8}$. This technology can overcome the limitations of both static cell cultures and animal studies ${ }^{8-10:} 1$ ) the inherent continuous flow in microfluidic devices enables continuous nutrient/oxygen supply and waste removal to maintain a stable growth environment for cells therein; 2) flow manipulation can apply desired gradients to the cells, which is especially useful for dosing studies; 3 ) the laminar flow in microfluidic channels can mimic blood physics in capillaries

- shear stress can be introduced, and multiple cell types can be connected for inter-tissue modelling; 4) human cells are commonly used to obviate the inter-species discrepancy of animal models; and 5) with precise engineering, studying a single factor is more feasible with organs-on-a-chip than in animals. Due to these unique advantages, the organs-on-a-chip technology holds the promise to lessen the gap between pre-clinical and clinical studies ${ }^{5}$.

There have been fantastic reviews focusing on microfluidic designs (e.g. on-chip pumps) for organs-on-a-chip applications ${ }^{9,10}$. In this paper, we will discuss the topic from a new perspective: the ways that cells can be cultured in microfluidics; specifically, integration of scaffolding materials as 
ECM to support cell growth and functions. In our opinion, the first generation of "organ-on-a-chip" devices should be called "cell-on-a-chip" because cells were cultured as a monolayer on a side of a fluidic channel or on embedded porous membranes. Except for a few cell types, such as endothelial cells, such models do not recreate the complex 3D cell-cell interactions assisted by ECMs on the organ level. Accumulating evidence has revealed the importance of ECMs for in vitro cell cultures ${ }^{11}$ as the $3 \mathrm{D}$ environment is critical to maintain cell activities and functions including proliferation, migration, apoptosis, and responses to drugs, etc ${ }^{12}$. For instance, Chitcholtan et al observed decreased proliferation of RL95-2 and KLE cells when cultured in 3D spheroids as compared to 2D monolayers when exposed to the anti-cancer drugs doxorubicin and cisplatin ${ }^{13}$. Hakkinen reported that ECM is an essential factor controlling the migration of fibroblasts. By comparing the migration rates of fibroblasts cultured in $3 \mathrm{D}$ and $2 \mathrm{D}$ environments, fibroblasts had significantly higher migration rates in 3D matrices comprised of collagen or cell-derived matrices ${ }^{14}$. Kloss et al demonstrated that apoptosis was affected by ECM dimensionality, particularly in drug-response studies, as 3D cell cultures differ in surface area to volume ratio as compared to monolayers ${ }^{15}$. Further mechanism studies revealed that integrins and cadherins on the cell membrane can sense the ECM conditions (chemical composition and physical properties such as stiffness), and transduce the information intracellularly ${ }^{16}$. Pampaloni et al and Jensen et al recently provided thorough reviews on the significance of ECMs for cell cultures ${ }^{17}, 18$. Therefore, continuous efforts have recently been made to include ECM materials for 3D cell cultures or even co-cultures in microfluidic device. There are two main families of scaffolding materials for organs-on-a-chip: hydrogels and electrospun fibers. These will be thoroughly reviewed in the following subsections.

\section{HYDROGELS AS SCAFFOLDING MATERIALS FOR ORGANS-ON-A-CHIP}

\section{A brief overview of hydrogels}

Hydrogels are cross-linked 3D polymer networks containing large amounts of water up to $99 \%$ by weight ${ }^{19}$. Hydrogels are permeable because of their expanded microstructure that occurs due to the affinity of the polymer backbone to the solvent (water) molecules. As shown in Fig.1, when water penetrates the cross-linked network, the backbones are "pushed" outward to maximum due to the formation of hydrogen bonds ${ }^{20}$. The pore size of the hydrogel can be varied by altering the hydrogel chemistry and the degree of crosslinking ${ }^{21}$. 
Hydrogels can be sorted into three main categories: natural, synthetic, and hybrid materials. Natural hydrogel materials directly originate from animals or plants. Animal-sourced hydrogels such as collagen are cytocompatible, present native cell-binding ligands, and exhibit chemical properties reminiscent of native tissues ${ }^{22,23}$. However, these gels usually have limited mechanical strengths, long-term stability, and batch-to-batch reproducibility ${ }^{24}$. Synthetic hydrogels, which are chemically synthesized from precursor molecules, can be more reproducibly customized to desired mechanical properties but may require additional chemical modifications for cell adherence ${ }^{25,26}$. Hybrid hydrogels are synthesized from bio-sourced small molecules such as hyaluronic acid and amino acids. Mixtures of different types of hydrogels (copolymers) have also been utilized to complement each other's shortcomings ${ }^{27}$. Many factors should be considered when selecting a hydrogel for 3D cell culturing; the most important ones are cell compatibility, molecular diffusion rates, and mechanical properties ${ }^{28}$. There have been insightful reviews regarding hydrogel properties for cell cultures ${ }^{28,29}$ and thus we will not discuss it further.

\section{Extraction of natural hydrogel materials from animal tissues}

Native ECM molecules directly derived from animal tissue have garnered interest for 3D cell cultures ${ }^{30}$. For example, Matrigel, a hydrogel material extracted from decellularized murine tumors, has shown great success in tumor-modelling research because of the recapitulation of cancer cell microenvironments ${ }^{31}$. These molecules can be chemically functionalized and/or physically mixed with other polymers for optimal performance. Due to the high cost of such products from vendors, efforts have been made to develop protocols to extract ECM molecules, mainly collagen, from animal tissues ${ }^{32,33}$.

Collagen is the primary component of ECM in animals with two main broad types: fibrillar and non-fibrillar ${ }^{34}$. About $90 \%$ of collagen in human beings is fibrillar, the molecules of which form a triple helix fibrillar structure via hydrogen bonds induced by the abundant proline and hydroxyproline residues ${ }^{34,35}$. Telopeptides at both ends of a single fibrillar molecule contain a high level of lysine and hydroxylysine, which can intermolecularly form aldol crosslinks via the enzyme lysyl oxidase ${ }^{36}$. A schematic representation for the formation of collagen ${ }^{37}$ can be seen in Fig. 2.

The intermolecular crosslinks must be broken in order to extract collagen from solid animal tissue. The most commonly used techniques for this purpose are acid/base treatment and enzymatic digestion ${ }^{38,39}$. Acids/bases are used for hydrolysis of native collagen and result in partially hydrolysed structures (gelatin) ${ }^{38}$. Mineral acids, specifically acetic acid, are most often used for hydrolysis of collagen ${ }^{38,40}$. The enzyme pepsin can be applied to increase the solubility 
of collagen due to its ability to cleave the intermolecular aldol crosslinks of the telopeptides ${ }^{38,41}$, 42. Following pre-treatment to remove cells and soluble proteins, additional steps may be performed to remove other components such as the removal of excess fats via butanol ${ }^{43}$. Examples of these steps are shown in Table 144-48. The extraction conditions listed do not outline additional purification steps which may be needed (e.g. using dialysis to remove pepsin (35 kDa)). It is common for steps to be performed at $4{ }^{\circ} \mathrm{C}$ to prevent thermal degradation of the material.

\section{Integration of hydrogels in microfluidics for organs-on-a-chip}

After considering the type of hydrogel to be used, the next step is to determine how to apply it. On the macro scale it is a matter of dispersing the uncured hydrogel material and then crosslinking it. However, this methodology is not suitable when micron resolution is required for biomimetic devices. Ultimately, strategies for incorporating hydrogels in microfluidic devices will be based on either fabricating a device with hollow channels and filling them with a curable hydrogel, or excising channels from a hydrogel bulk material. The technique used is dictated by the resolution and complexity of the part of interest ${ }^{49,50}$.

\section{Filling hydrogels in pre-made microfluidic devices}

Hydrogels can be filled in premade microfluidic devices as ECMs for 3D cell culture. For example, Virumbrales-Muñoz et al. investigated the ability of TNF-related apoptosis inducing ligand (TRAIL) to penetrate endothelium and kill tumor cells in a 3D collagen matrix. The microfluidic device was fabricated from polydimethylsiloxane (PDMS) via soft lithography. The central channel was oxygen plasma treated to promote capillary actions for spontaneous filling. Droplets of collagen (1.2 mg/mL, see Ref. 51 for details), which were previously mixed 1:1(v/v) with the cancer cell suspension, were placed on top of the device inlet for filling. The collagen was then polymerized for 12 minutes at $37^{\circ} \mathrm{C}$. Endothelial cells were cultured in the flow path on top of the collagen containing the cancer cells (Fig. 3A). TRAIL was introduced both in its soluble form and bound to a large unilamellar vesicle ${ }^{51}$. A similar device but with two unique hydrogel constructs was prepared by Adriani et al. to model the blood brain barrier and how drugs can potentially affect neurocytes and astrocytes ${ }^{52}$ (Fig. 3B). Here collagen solutions with suspended astrocytes $\left(0.6 \times 10^{6}\right.$ cells $\left./ \mathrm{mL}\right)$ and neurons $\left(5 \times 10^{6}\right.$ cells $\left./ \mathrm{mL}\right)$ were injected directly into the device and then polymerized for 30 minutes at $37^{\circ} \mathrm{C}$. Pavesi et al. utilized a microfluidic device with a collagen barrier separating two microfluidic channels. Similarly, cells were suspended in the

hydrogel solution $\left(5 \times 10^{6}\right.$ cells $\left./ \mathrm{mL}\right)$, injected directly into the region of interest, and allowed to 
polymerize for 40 minutes at $37^{\circ} \mathrm{C}$. The microfluidic channels would flow tumor-specific T-cell receptor T (TCR-T) cells parallel to the hydrogel which contained human hepatocytes. The efficacy of the TCR-T cells were then observed under different oxygen conditions and in the presence of inflammatory cytokines ${ }^{53}$ (Fig. 3C). Jeong et al. further developed this technology by creating a seven-channel device for studying the effects of tumor spheroids on fibroblast activity (Fig. 3D) $)^{54}$.

The examples described above represent a common methodology for including cell-laden hydrogels in existing microfluidic devices, where the prepolymer of the gel is delivered to fill a channel or chamber via capillary action and is held in place by surface tension. After subsequent curing media is perfused through an adjacent channel, which contacts one side of the gel structure, for nutrients and oxygen to be transported to the cells therein through diffusion. While simple and straightforward, this method has challenges in specific applications. First, it suspends cells in a gel without considering cell alignments. Many cell types such as skeletal muscle fibers need to be aligned to exert normal functions ${ }^{55}$. Second, the lateral flow of media along the surface of a gel and the diffusion mechanism for supplying nutrients and removal of waste may be limited in terms of efficiency - evidence shows that a gel thicker than $200 \mu \mathrm{m}$ can cause cell necrosis due to insufficient oxygen delivery ${ }^{56}$. To circumvent these issues, precise gel localization using photolithography has been developed. For example, Agrawal et al demonstrated an innovative muscle-on-a-chip model using a photomask to specifically form two hydrogel pillars $(100-300 \mu \mathrm{m})$ within a microfluidic channel. Next, GelMA containing C2C12 muscle cells was cured in a capsule shape between the pillars using a second photomask. The results showed that the micropillars acted as anchoring points to force the cells to form uniaxially-aligned, densely-packed 3D muscle cylinders $^{57}$. Skardal et al recently created a liver-on-a-chip model with enhanced molecular diffusion through hydrogel. A photomask was applied to form islets of cell-laden hydrogels within flow paths, such that media could flow around the islets and molecules diffusing from all sides of the gel structure ${ }^{58}$. With this design, liver cells (HEPG2) were alive and functional for over seven days ${ }^{58}$. Overall, photolithography-assisted hydrogel inclusion in microfluidic devices provides precise localization and patterning of cells. However, it usually requires UV light to cure the gels which may cause phototoxicity issues. All these factors should be considered when choosing a method for organs-on-a-chip research. 
Fabrication of microchannels in hydrogel parts

\section{Replica Molding}

Replica molding can be used to make microfluidics in hydrogels without photocuring limitations. There are three types of molds that are commonly used to cast hydrogel-based microfluidic devices: master molds prepared by photolithography, physically removable molds, and sacrificial molds. As shown in Fig. 4A, a master can be prepared by allowing irradiation to pass through the transparent pattern on the photomask, which cross-links the photoresist material (e.g. SU-8) in place, creating a raised serpentine microstructure (Fig. 4B). Next, the prepolymer of a hydrogel is poured onto the mold (Fig. 4C) followed by gelation. After the hydrogel slab is peeled off, it can be sealed to a substrate such as glass to close the channel for flow-based experiments (Fig. 4D). For example, Cabodi et al. utilized this technology to fabricate a microfluidic device by casting an alginate solution on top of a patterned photoresist prepared via lithography 59 . The cross-sections of microchannels fabricated by this method are typically rectangular, but research into scaffold geometry indicates that cell adhesion is affected by the shape of the substrate, where rectangular (cross section) channels show a lower degree of cell adhesion $^{60}$. Therefore, He et al. developed a more complicated methodology for fabricating hydrogels with circular channels to better emulate internal vasculature. This was accomplished by partially crosslinking gelatin which was cast on a semi-circle mold, aligning it with another gelatin cast, and completing the crosslinking to form circular hollow channels ${ }^{61}$. The way that a closed microfluidic channel is formed (binding a hydrogel layer on a substrate) can be challenging in subsequent applications. Due to the flexibility of hydrogels, deformation will likely occur when placing a gel layer on a substrate (e.g., stretching), which can compromise the dimensions and shapes of the desired microstructures. Using less flexible hydrogels and alignment markers can be a potential solution to this issue ${ }^{62}$. Some groups measured the amount of shrinkage that occurred under different conditions and adjusted the mold pre-emptively for curing results in the desired final dimensions ${ }^{63}$.

Existing microstructures such as micron-diameter wires can also be embedded in hydrogels to form microchannels. For example, Linville and Wong prepared hollow microfluidic channels in hydrogel-based devices by crosslinking polymers such as collagen and agarose around a wire which was pulled out after the hydrogel gelated ${ }^{64,65}$ (Figs. 4E and 4F). It is simple and straightforward to fabricate devices using such physically removable molds. However, this method can only generate devices with basic and simple microstructures (e.g. straight channels). 
Sacrificial molds can be used to fabricate complicated hollow microstructures in a piece of hydrogel. These molds are made by certain materials such as gelatin ${ }^{66}$, PVA (polyvinyl alcohol $)^{67}$, and alginate ${ }^{68}$ which can be dissolved after the surrounding hydrogel is fully cured. A recent example is by Tocchio et al.; a mold was etched in plexiglass, PVA was carefully poured into it, dried overnight, and removed ${ }^{67}$ (Fig. 5A). This mold was then placed between glass spacers and covered in either 2-hydroxyethyl methacrylate (HEMA), agarose, or GelMA ${ }^{67 .}$ Following curation of the hydrogels and removal of the spacers, the PVA was dissolved by washing with water or phosphate-buffered saline ${ }^{67}$ to form hollow channels in the hydrogel (Fig. 5B) which could be seeded with endothelial cells to mimic a vasculature system (Fig. 5C). Sacrificial molds provide a low-cost way to fabricate desired microstructures in hydrogel. However, certain concerns may arise from the additional washing step: the buffer composition may cause chemical contamination and/or osmotic shock to the cells; maintaining sterilization may also be difficult.

Overall, replica molding is a simple technique to fabricate hydrogel microfluidic devices, however, limitations and challenges exist. To maintain the structural integrity of such a device, relatively stiff materials are commonly used which may not support viable cell encapsulation due to the high material density (e.g. limited number and size of the pores for diffusion). This perhaps explains why these studies mainly used the inner wall of the microchannels as a support surface to seed endothelial cells as a vasculature mimic. In addition to the deformation issue of microstructures in a soft gel, ports at the ends of flow channels to connect tubing and adaptors for liquid delivery/perfusion can also be challenging. The most frequently used method for creating ports is using punchers, which excise a portion of the hydrogel of the punch's diameter. Currently, the success of this method relies on user expertise both for using punchers and appropriately curing the hydrogel device, and the flexible gel may not be able to seal a tubing tightly for leakagefree flows. To circumvent these issues, efforts will be needed for new device designs and fabrications. For instance, the device shown in Fig. 4E was not connected to tubing. Instead, the device was placed vertically with a reservoir on top filled with media, and gravity drove the flow through the channel. Multiple materials can also be used to fabricate such a device, with gels of high mechanical strengths in the port area for reliable port punching. 


\section{$3 D$ bioprinting}

Extrusion-based bioprinting has gained interest in recent years for creating tissue models due to its capability for fabricating 3D structures with desired dimensions and shapes in one step ${ }^{69}$. A typical 3D bioprinting process is to extrude bioinks (e.g. hydrogel prepolymer with suspended cells) onto a stage layer by layer ${ }^{69}$. Each layer is cured via various mechanisms such as photo irradiation and chemical crosslinkers. Fig. 6 illustrates how a 3D bioprinter works with optical components to cure the gel. Numerous bioprinted tissue models have been reported. For example, Cao et al. directly printed a mixture of either PEGDA or poly(ethylene glycol) octaacrylate (PEGOA) with GelMA, alginate, and photoinitiator to form microfluidic tubes ${ }^{70}$ (Fig. 7). These printed tubes acted as blood and lymphatic vessel mimics which were then sealed within a GeIMA matrix containing suspended MCF-7 tumor cells. Therefore, a tumor model that contained blood flow, lymphatic drainage, and cancer cells embedded in surrounding hydrogels was fabricated ${ }^{70}$.

To avoid the cytotoxicity issue of common photoinitiators, Grigoryan et al. recently reported that biocompatible food color molecules can be used to cure PEGDA hydrogels ${ }^{71}$. They also developed a home-made digital micro-mirror setup for the fabrication of complicated microchannel networks. They first manufactured an acellular interconnected channel network to study the oxygenation of red blood cells (Fig. 8), which was achieved by using a $20 \%$ (w/w) by weight PEGDA (6 kDa) solution, as this gel was determined to allow for oxygen diffusion and relatively long-term mechanical stability (device could withstand 10,000 ventilation cycles). Although not stated by the authors, it is likely that the PEGDA hydrogel may be too dense to encapsulate cells for direct tissue printing, because in a subsequent experiment, the authors fabricated a PEGDA holder with a prefill space, where fibroin or GelMA gels with suspended hepatocyte aggregates were filled and cured in situ.

Recreating an accurate in vivo mimic often requires the use of multiple materials to simulate the different parts of an organ/tissue ${ }^{72}$; fabrication of such systems can be carried out by 3D bioprinting. For example, Ruiz-Cantu et al. produced a neocartilage model using chondrocyteladen GelMA co-printed with polycaprolactone $(P C L)^{72}$. Kang et al. bioprinted a fine-tuned mixture of gelatin, fibrinogen, hyaluronic acid, and glycerol prepared in Dulbecco's Modified Eagle Medium (DMEM) to make ear constructs ${ }^{73}$. These constructs were implanted in mice and were observed to retain structural integrity over two months and showed signs of surface 
vascularization ${ }^{73}$. Arumugasaamy et al. recently reviewed multimaterial bioprinting and its applications at length ${ }^{74}$.

The historical drawback of $3 \mathrm{D}$ bioprinting is the low resolution due to the flexibility of the bioinks and the relatively slow kinetics for curing the hydrogel matrix ${ }^{75}$. However, recent advances have lowered the achievable resolution making it a more attractive option ${ }^{76-78}$. An example of such is light-assisted printing where the resolution is dependent on the light source rather than the printing head of an extruder ${ }^{69}$. Light-assisted techniques have their own drawbacks, such as potential cytotoxicity and limitations in printing materials, but are able to push printing resolutions down to $5 \mu \mathrm{m}$ or lower whereas extrusion-based methods are currently limited to $100 \mu \mathrm{m}$ and higher ${ }^{69}$. Another concern of 3D bioprinting is the high shear stress expressed to the cells. When a stream of bioink with cells is pushed out of the extruder orifice, the cells are experiencing a high level of shear, which may be deleterious for the cells ${ }^{79}$. This is especially true when applying a smaller orifice to improve resolution ${ }^{79}$.

Like the replica molding technology, 3D-bioprinting also makes microfluidic devices from hydrogels-a stiff and dense gel can maintain the structural integrity but compromise cell viability therein. In an analysis of recent publications, the reported bioprinted devices can be grouped into two categories: those with cells encapsulated to mimic a tissue in vivo, and others that act merely as a support structure for subsequent cell seeding or perfusion (e.g. erythrocytes perfused through a device to mimic blood flow, the example in Fig. 8). In the case of the former, it is exceedingly important that the hydrogel chemistry and physics can mimic the in vivo environment. Specifically, the bioink used during 3D printing must provide cell adhesion moieties, be permeable for oxygen and small molecules, and be mechanically stable ${ }^{80,81}$. Common naturally occurring materials used as bioinks are those based on agarose, alginate, collagen, and hyaluronic acid ${ }^{80}$. Agarose dissolves and is handled easily, gels at low temperatures, and maintains dimensionality for long periods of time ${ }^{81}$. However, low cell adhesion and proliferation as well as limited biosynthesis of cell components has indicated that agarose on its own is insufficient for cell culturing $^{82,83}$. Kreimendahl et al demonstrated the feasibility of blending agarose with collagen and fibrinogen to promote cell culturing while maintaining structural stability ${ }^{84}$. Alginate is a commonly used material owing to its abundance, low cost, and characterized diffusion properties $^{85}$. Furthermore, alginate can be cured significantly quicker than thermally-cured hydrogels through the use of multivalent cations ${ }^{85}$. However, monolithic alginate hydrogels lack mechanical stability and adhesion sites, limiting cell attachment ${ }^{81}$. Strategies to overcome these shortcomings have been demonstrated; Jia et al developed a mixture of alginate, GeIMA, and PEG-tetra-acrylate (PEGTA) to form a high-strength device with perfusable vasculature ${ }^{86}$. 
Functionalization of alginate channels with specific peptides has also been demonstrated to promote cell adhesion ${ }^{87}$. Although collagen is commonly used for cell culturing, it is difficult to be used for 3D bioprinting due to its long cure times, during which homogeneity of cell distribution may be lost as cells spread ${ }^{81}$. Modified collagens have made it a viable bioprinting material. For instance, Homenick et al demonstrated this by crosslinking collagen with poloxamers to increase the Young's modulus of the overall material| ${ }^{81}$. Overall, as natural materials have low tunability of their mechanical properties, it is simpler to blend them with synthetics which can have various properties (e.g. molecular weight, degree of functionality, types of functional groups) adjusted based on the needs of the application ${ }^{80}$.

When hydrogels are used as a microfluidic device material to support subsequent cell inclusion, maintaining mechanical stability becomes a necessity along with other considerations such as non-specific molecular adsorption/absorption and surface tensions ${ }^{88}$. Protocols have been reported to functionalize parts of such as device for specific cell applications. For example, Koh et al formed microwells for the isolated culturing of cells by fabricating a layer of PEG hydrogel walls which circumscribed a hydrophobic floor to selectively pattern cells ${ }^{89}$. A similar approach was shown by Lee et al where micropatterned PEG hydrogels, acting as walls/dividers, were placed over a network of electrospun fibers for the localization of cells ${ }^{90}$.

In conclusion, with current technologies, it is critical to choose a proper material for 3Dbioprinting. In addition to the chemistry of a material, the curing conditions (e.g. temperature, time, radiation, etc.) can also affect the crosslink density, porosity, and mechanical properties, which need to be optimized for each specific application.

\section{ELECTROSPUN FIBERS AS SCAFOLDING MATERIALS FOR ORGANS-ON-A-CHIP}

\section{An overview of electrospinning}

The technology of electrospinning

Electrospinning is a technique that utilizes a high electrical voltage to generate polymer fibers on the micro- and nanometer scale ${ }^{91}$. As shown in Fig. 9, a typical electrospinning setup consists of a syringe for dispensing a polymer solution through a metal needle. A high voltage (in the range of $5-30 \mathrm{kV}$ ) is applied to the metal needle, where a Taylor cone forms ${ }^{92}$. The fibers are electrically charged and thus can be deposited on a grounded collector. Due to the tuneable fiber 
diameter and mechanical stiffness, and the ability to embed particles/compounds, electrospun fibers have been utilized in various applications as scaffolding materials for 3D cell culture ${ }^{93-96}$.

\section{Commonly used polymers in electrospinning}

Both synthetic and natural polymers have been implemented in electrospinning; some of the most commonly used ones are summarized in Table 2. After a literature search via Web of Science using keywords "Electrospinning" and "Extracellular Matrix", it was determined that PCL (polycaprolactone) and PLA (polylactic acid) are the two most common materials due to their biocompatibility and biodegradable nature ${ }^{97-100}$. Fig. 10A shows the popularity of the materials for electrospinning ${ }^{101-195}$. Most of the research implementing electrospinning focuses on biomimetic tissue engineering such as 3D cell cultures (Fig. 10B).

In addition to synthesized polymers, the use of natural polymers for electrospinning was also explored. For example, collagen and fibronectin solutions can be directly electrospun to generate more physiologically relevant ECMs than synthetic polymers ${ }^{196}$. Silk fibroin has been gaining attention recently due to its remarkable characteristics including biocompatibility, high water and oxygen uptake, and tunable mechanical properties ${ }^{197}$. This material can be extracted from raw silk following a simple protocol at low costs ${ }^{198}$.

\section{Integration of electrospun fibers in microfluidics for organs-on-a-chip studies}

Most of the applications of electrospun fibers have used static containers to culture cells. A standard protocol is to peel the electrospun fiber layer off from the collector, cut it to the desired shape, and then place it in a multi-well plate for cell seeding after sterilization ${ }^{199}$. Although simple, this protocol excludes the potential benefits of flow-based cell cultures such as shear stress introduction, continuous nutrient supply and waste removal, and gradient control. Therefore, since 2016, efforts have been made to combine electrospun fibers as scaffolding materials in microfluidics to prototype organs-on-a-chip models. There are three main technologies developed 
for this purpose: lateral-flow models, direct electrospinning of fibers into a microfluidic channel, and modular integration of electrospun fibers.

\section{$\underline{\text { Lateral-flow model }}$}

Pimentel et al. recently developed a microfluidic device on a sheet of electrospun fibers (Poly(L-lactic acid), PLLA)) as a lateral-flow model for cell culture 200 . As shown in Fig. 11A, certain areas on a sheet of electrospun fibers (the whole square) were blocked to form hydrophobic barriers (black; blocking material was not specified by the authors) surrounding channels and circular zones. Like paper-based microfluidics, the fibrous nature of the substrate can drive liquid flow via capillary actions. However, compared to paper, electrospinning offers the possibility to make fibers of desired dimensions and morphologies (Fig. 11B) for specific cell culture applications. Also, other components can be premixed in the polymer solution to make composite fibers. For example, the authors added $\mathrm{NaY}$, a crystal sodium zeolite, to the fiber to increase the hydrophilicity of the material ${ }^{178}$.

This technology has unique advantages including simple fabrication and assay parallelization (multiple chambers in one device). However, such devices are not suitable for cell types that require flow-based shear stress.

\section{Direct Electrospinning of Fibers into a Microfluidic Channel}

Chen et al. invented a technology in 2016 called dynamic focusing electrospinning, to directly coat electrospun fibers on the inner side of a fluidic channel201. As demonstrated in Fig. 12A, a 3D-printed sheath device was placed around the metal needle/cannula. With proper pressure, the gas (air or $\mathrm{N}_{2}$ ) flowing out of the sheath confined the PCL fibers through the fluidic channel placed under the Taylor cone. The exiting fibers from the bottom end of the fluidic device indicated successful fiber coating inside the channel. A uniform layer of microfibers was added to the channel wall, which was confirmed by SEM imaging (Fig. 12B). The authors cultured RAW 
264.7 macrophages and found that the fibrous scaffold enhanced the production of cytokines such as interleukin-6 (IL-6) and vascular endothelial growth factor (VEGF).

This technology can introduce the flow through a 3D tissue mimic. However, a limitation is that the diameter of the fluidic channel cannot be smaller than $1 \mathrm{~mm}$. Although the fibers can be focused by the sheath flow, there is a limit of the focusing because the fibers tend to spread due to the same charges they bear. Also, the pressure of the gas flow cannot be too high, or disruption of the Taylor cone will occur.

\section{Modular Integration of Electrospun Fibers in Microfluidic Devices}

Chen et al. reported another technology to modularly integrate fibers in microfluidics in 2018202. As shown in Fig. 13A, instead of directly electrospinning into a microfluidic channel, the fibers were coated on a polystyrene sheet first, which was then laser cut into rectangular inserts ${ }^{203}$. The fused edges by the laser immobilized the fibers on the PS substrate. After cells were seeded on the fibers, the inserts were plugged into a 3D-printed fluidic device with matching slots (Fig. 13B). The space between the inserts form the fluidic channel for media to flow through (Figs. 13C and 13D). The authors demonstrated that under lipopolysaccharide (LPS) stimulation, the response rates of macrophages cultured in the fibrous scaffolds are more physiologically relevant than those cultured on a flat surface.

This technology has prominent advantages. Modularity allows for examination of the cells cultured on the inserts before assembly, with failed cultures (e.g. by contamination) being replaced without discarding the whole setup. After an experiment, the cell-laden inserts can be

removed for further studies such as imaging. The space between inserts is customizable for tuning shear stress. In our opinion, this is the most applicable technology for integrating electrospun fibers in microfluidics to date. 


\section{CONCLUSION AND PERSPECTIVE}

In this paper, we thoroughly reviewed recent (mainly after 2016) advances in integrating scaffolding materials in microfluidics for organs-on-a-chip applications. Various technologies have been developed to incorporate hydrogel materials and electrospun fibers on chips for disease modeling, pathophysiological studies, and pharmaceutical research, with insightful results generated. After reviewing these models, we found that they were fabricated by complicated protocols via high-end/expensive instruments, which may explain why the technologies have not been widely translated. Organs-on-a-chip hold the potential for extensive breakthroughs in disease modeling, drug discovery, and enhancing our understanding of organ functions. However, this promising potential will not be achieved without easy translation of the technology to other laboratories (e.g. those with expertise in physiology but not chip fabrication). Simplified and translational devices should be a research focus in the future. Modularity can help technology translation; compared to all-in-one devices which must be discarded if any part fails, modular microfluidic devices are more cost-efficient and flexible. For example, a toolkit with various modules can be developed, with which organs-on-a-chip models can be simply assembled based on specific needs. Also, protocols need to be standardized. For instance, to cure collagen hydrogel at $37^{\circ} \mathrm{C}$, different curing times have been reported. Standardizing such protocols will benefit technology translation. Lastly, most of the reported organs-on-a-chip models were singleuse devices with only one throughput. Considering the high labor, time, and facility investments to the fabrication, these factors can depress enthusiasm. Therefore, reusable devices with enhanced throughput need to be exploited. 


\section{REFERENCES}

1. DiMasi, J. A.; Grabowski, H. G.; Hansen, R. W., Innovation in the pharmaceutical industry: New estimates of R\&D costs. J Health Econ 2016, 47, 20-33.

2. Zhang, B. Y.; Radisic, M., Organ-on-a-chip devices advance to market. Lab Chip 2017, 17 (14), 2395-2420.

3. Ghanemi, A., Cell cultures in drug development: Applications, challenges and limitations. Saudi Pharm J 2015, 23 (4), 453-454.

4. $\quad$ Tyers, M.; Mann, M., From genomics to proteomics. Nature 2003, 422 (6928), 193-197.

5. Sakolish, C. M.; Esch, M. B.; Hickman, J. J.; Shuler, M. L.; Mahler, G. J., Modeling Barrier Tissues In Vitro: Methods, Achievements, and Challenges. Ebiomedicine 2016, 5, 30-39.

6. Wu, M. H.; Huang, S. B.; Lee, G. B., Microfluidic cell culture systems for drug research. Lab Chip 2010, 10 (8), 939-956.

7. Whitesides, G. M., The origins and the future of microfluidics. Nature 2006, 442 (7101), 368-373.

8. $\quad$ Polini, A.; Prodanov, L.; Bhise, N. S.; Manoharan, V.; Dokmeci, M. R.; Khademhosseini, A., Organs-on-a-chip: a new tool for drug discovery. Expert Opin Drug Dis 2014, 9 (4), 335-352.

9. Ronaldson-Bouchard, K.; Vunjak-Novakovic, G., Organs-on-a-Chip: A Fast Track for Engineered Human Tissues in Drug Development. Cell Stem Cell 2018, 22 (3), 310-324.

10. Ishida, S., Organs-on-a-chip: Current applications and consideration points for in vitro ADME-Tox studies. Drug Metab Pharmacok 2018, 33 (1), 49-54.

11. Dutta, R. C.; Dutta, A. K., Cell-interactive 3D-scaffold; advances and applications. Biotechnol Adv 2009, 27 (4), 334-339.

12. Bissell, M. J.; Radisky, D. C.; Rizki, A.; Weaver, V. M.; Petersen, O. W., The organizing principle: microenvironmental influences in the normal and malignant breast. Differentiation 2002, 70 (9-10), 537-46.

13. Chitcholtan, K.; Sykes, P. H.; Evans, J. J., The resistance of intracellular mediators to doxorubicin and cisplatin are distinct in 3D and 2D endometrial cancer. J Transl Med 2012, 10, 38.

14. Hakkinen, K. M.; Harunaga, J. S.; Doyle, A. D.; Yamada, K. M., Direct comparisons of the morphology, migration, cell adhesions, and actin cytoskeleton of fibroblasts in four different three-dimensional extracellular matrices. Tissue Eng Part A 2011, 17 (5-6), 713-24.

15. Kloss, D.; Kurz, R.; Jahnke, H. G.; Fischer, M.; Rothermel, A.; Anderegg, U.; Simon, J. C.; Robitzki, A. A., Microcavity array (MCA)-based biosensor chip for functional drug screening of 3D tissue models. Biosens Bioelectron 2008, 23 (10), 1473-80.

16. Janmey, P. A.; Fletcher, D. A.; Reinhart-King, C. A., Stiffness Sensing by Cells. Physiological Reviews 2019, 100 (2), 695-724.

17. Pampaloni, F.; Reynaud, E. G.; Stelzer, E. H., The third dimension bridges the gap between cell culture and live tissue. Nat Rev Mol Cell Biol 2007, 8 (10), 839-45.

18. Jensen, C.; Teng, Y., Is It Time to Start Transitioning From 2D to 3D Cell Culture? Frontiers in Molecular Biosciences 2020, 7, 33.

19. Peppas, N. A., Biomedical applications of hydrogels handbook. Springer Science \& Business Media: 2010.

20. Osada, Y.; Ping Gong, J.; Tanaka, Y., Polymer Gels. Journal of Macromolecular Science, Part C 2004, 44 (1), 87-112.

21. Chavda, H.; Patel, C., Effect of crosslinker concentration on characteristics of superporous hydrogel. International journal of pharmaceutical investigation 2011, 1 (1), 17-21.

22. Dong, C.; Lv, Y., Application of Collagen Scaffold in Tissue Engineering: Recent Advances and New Perspectives. Polymers 2016, 8 (2), 42. 
23. Liu, H.; Wang, Y.; Cui, K.; Guo, Y.; Zhang, X.; Qin, J., Advances in Hydrogels in Organoids and Organs-on-a-Chip. Advanced Materials 2019, 31 (50).

24. Kreger, S. T.; Bell, B. J.; Bailey, J.; Stites, E.; Kuske, J.; Waisner, B.; Voytik-Harbin, S. L., Polymerization and matrix physical properties as important design considerations for soluble collagen formulations. Biopolymers 2010, 93 (8), 690-707.

25. Lee, K. Y.; Mooney, D. J., Hydrogels for tissue engineering. (0009-2665 (Print)).

26. Jia, X.; Kiick, K. L., Hybrid multicomponent hydrogels for tissue engineering.

Macromolecular bioscience 2009, 9 (2), 140-156.

27. Chuang, C. H.; Lin, R. Z.; Melero-Martin, J. M.; Chen, Y. C., Comparison of covalently and physically cross-linked collagen hydrogels on mediating vascular network formation for engineering adipose tissue. Artif Cells Nanomed Biotechnol 2018, 46 (sup3), S434-S447.

28. Caliari, S. R.; Burdick, J. A., A practical guide to hydrogels for cell culture. Nature Methods 2016, 13 (5), 405-414.

29. Utech, S.; Boccaccini, A. R., A review of hydrogel-based composites for biomedical applications: enhancement of hydrogel properties by addition of rigid inorganic fillers. $J$ Mater Sci 2016, 51 (1), 271-310.

30. Lu, H.; Hoshiba, T.; Kawazoe, N.; Koda, I.; Song, M.; Chen, G., Cultured cell-derived extracellular matrix scaffolds for tissue engineering. Biomaterials 2011, 32 (36), 9658-9666.

31. Cavo, M.; Caria, M.; Pulsoni, I.; Beltrame, F.; Fato, M.; Scaglione, S., A new cell-laden 3D Alginate-Matrigel hydrogel resembles human breast cancer cell malignant morphology, spread and invasion capability observed "in vivo". Scientific Reports 2018, 8 (1), 5333.

32. Dippold, D.; Cai, A.; Hardt, M.; Boccaccini, A. R.; Horch, R. E.; Beier, J. P.; Schubert, D. W., Investigation of the batch-to-batch inconsistencies of Collagen in PCL-Collagen nanofibers. Materials Science and Engineering: C 2019, 95, 217-225.

33. Tang, C.; Holt, B. D.; Wright, Z. M.; Arnold, A. M.; Moy, A. C.; Sydlik, S. A., Injectable amine functionalized graphene and chondroitin sulfate hydrogel with potential for cartilage regeneration. Journal of Materials Chemistry B 2019, 7 (15), 2442-2453.

34. Ricard-Blum, S., The collagen family. Cold Spring Harb Perspect Biol 2011, 3 (1), a004978.

35. Fratzl, P., Collagen. Springer US: 2008.

36. Maki, J. M., Lysyl oxidases in mammalian development and certain pathological conditions. Histol Histopathol 2009, 24 (5), 651-60.

37. Meyer, M., Processing of collagen based biomaterials and the resulting materials properties. Biomed Eng Online 2019, 18 (1), 24.

38. Schmidt, M.; Dornelles, R.; Mello, R.; Kubota, E.; Mazutti, M.; Kempka, A.; Demiate, I., Collagen extraction process. International Food Research Journal 2016, 23 (3).

39. Cersoy, S.; Zazzo, A.; Lebon, M.; Rofes, J.; Zirah, S., Collagen Extraction and Stable Isotope Analysis of Small Vertebrate Bones: A Comparative Approach. Radiocarbon 2017, 59, 679-694.

40. Liu, D.; Wei, G.; Li, T.; Hu, J.; Lu, N.; Regenstein, J. M.; Zhou, P., Effects of alkaline pretreatments and acid extraction conditions on the acid-soluble collagen from grass carp (Ctenopharyngodon idella) skin. Food Chemistry 2015, 172, 836-843.

41. Qian, J.; Okada, Y.; Ogura, T.; Tanaka, K.; Hattori, S.; Ito, S.; Satoh, J.; Takita, T.; Yasukawa, K., Kinetic Analysis of the Digestion of Bovine Type I Collagen Telopeptides with Porcine Pepsin. Journal of Food Science 2016, 81 (1), C27-C34.

42. Hickman, D.; Sims, T. J.; Miles, C. A.; Bailey, A. J.; de Mari, M.; Koopmans, M., Isinglass/collagen: denaturation and functionality. J Biotechnol 2000, 79 (3), 245-57.

43. Song, W., Extraction Optimization and Characterization of Collagen from the Lung of Soft-Shelled Turtle Pelodiscus Sinensis. International Journal of Nutrition and Food Sciences 2014, 3, 270. 
44. Yang, H.; Shu, Z., The extraction of collagen protein from pigskin. Journal of chemical and pharmaceutical research 2014, 6 (2), 683-687.

45. Noitup, P.; Garnjanagoonchorn, W.; Morrissey, M. T., Fish Skin Type I Collagen. Journal of Aquatic Food Product Technology 2005, 14 (1), 17-28.

46. Paola, C.; Camila, A.; Ana, C.; Marlon, O.; Diego, S.; Zuluaga, R.; Beatriz, G.; Cristina, C., Functional textile finishing of type I collagen isolated from bovine bone for potential healthtech. Heliyon 2019, 5, e01260.

47. Nagai, T.; Tanoue, Y.; Kai, N.; Suzuki, N., Characterization of collagen from emu (Dromaius novaehollandiae) skins. Journal of food science and technology 2015, 52 (4), 23442351.

48. Liu, W.; Zhang, Y.; Cui, N.; Wang, T., Extraction and characterization of pepsinsolubilized collagen from snakehead (Channa argus) skin: Effects of hydrogen peroxide pretreatments and pepsin hydrolysis strategies. Process Biochemistry 2019, 76, 194-202.

49. Sung, J. H.; Yu, J.; Luo, D.; Shuler, M. L.; March, J. C., Microscale 3-D hydrogel scaffold for biomimetic gastrointestinal (GI) tract model. Lab Chip 2011, 11 (3), 389-92.

50. Khademhosseini, A.; Langer, R., Microengineered hydrogels for tissue engineering. Biomaterials 2007, 28 (34), 5087-92.

51. Virumbrales-Muñoz, M.; Ayuso, J. M.; Olave, M.; Monge, R.; de Miguel, D.; MartínezLostao, L.; Le Gac, S.; Doblare, M.; Ochoa, I.; Fernandez, L. J., Multiwell capillarity-based microfluidic device for the study of 3D tumour tissue-2D endothelium interactions and drug screening in co-culture models. Scientific Reports 2017, 7 (1), 11998.

52. Adriani, G.; Ma, D.; Pavesi, A.; Kamm, R. D.; Goh, E. L. K., A 3D neurovascular microfluidic model consisting of neurons, astrocytes and cerebral endothelial cells as a bloodbrain barrier. Lab on a Chip 2017, 17 (3), 448-459.

53. Pavesi, A.; Tan, A. T.; Koh, S.; Chia, A.; Colombo, M.; Antonecchia, E.; Miccolis, C.; Ceccarello, E.; Adriani, G.; Raimondi, M. T.; Kamm, R. D.; Bertoletti, A., A 3D microfluidic model for preclinical evaluation of TCR-engineered T cells against solid tumors. JCI Insight 2017, 2 (12).

54. Jeong, S.-Y.; Lee, J.-H.; Shin, Y.; Chung, S.; Kuh, H.-J., Co-Culture of Tumor Spheroids and Fibroblasts in a Collagen Matrix-Incorporated Microfluidic Chip Mimics Reciprocal Activation in Solid Tumor Microenvironment. PloS one 2016, 11 (7), e0159013e0159013.

55. Zhao, Y.; Zeng, H.; Nam, J.; Agarwal, S., Fabrication of skeletal muscle constructs by topographic activation of cell alignment. Biotechnology and bioengineering 2009, 102 (2), 624631.

56. Zhu, W.; Qu, X.; Zhu, J.; Ma, X.; Patel, S.; Liu, J.; Wang, P.; Lai, C. S. E.; Gou, M.; $\mathrm{Xu}, \mathrm{Y}$.; Zhang, K.; Chen, S., Direct 3D bioprinting of prevascularized tissue constructs with complex microarchitecture. Biomaterials 2017, 124, 106-115.

57. Agrawal, G.; Aung, A.; Varghese, S., Skeletal muscle-on-a-chip: an in vitro model to evaluate tissue formation and injury. Lab on a Chip 2017, 17 (20), 3447-3461.

58. Skardal, A.; Devarasetty, M.; Soker, S.; Hall, A. R., In situ patterned micro 3D liver constructs for parallel toxicology testing in a fluidic device. Biofabrication 2015, 7 (3), 031001.

59. Cabodi, M.; Choi, N. W.; Gleghorn, J. P.; Lee, C. S.; Bonassar, L. J.; Stroock, A. D., A microfluidic biomaterial. J Am Chem Soc 2005, 127 (40), 13788-9.

60. Green, J. V.; Kniazeva, T.; Abedi, M.; Sokhey, D. S.; Taslim, M. E.; Murthy, S. K., Effect of channel geometry on cell adhesion in microfluidic devices. Lab Chip 2009, 9 (5), 67785.

61. He, J.; Chen, R.; Lu, Y.; Zhan, L.; Liu, Y.; Li, D.; Jin, Z., Fabrication of circular microfluidic network in enzymatically-crosslinked gelatin hydrogel. Materials Science and Engineering: C 2016, 59, 53-60. 
62. Mogi, K.; Fujii, T., A novel assembly technique with semi-automatic alignment for PDMS substrates. Lab on a Chip 2013, 13 (6), 1044-1047.

63. Lee, S. W.; Lee, S. S., Shrinkage ratio of PDMS and its alignment method for the wafer level process. Microsystem Technologies 2008, 14 (2), 205-208.

64. Wong, A. D.; Searson, P. C., Live-Cell Imaging of Invasion and Intravasation in an Artificial Microvessel Platform. Cancer Research 2014, 74 (17), 4937.

65. Linville, R. M.; DeStefano, J. G.; Sklar, M. B.; Xu, Z.; Farrell, A. M.; Bogorad, M. I.; Chu, C.; Walczak, P.; Cheng, L.; Mahairaki, V.; Whartenby, K. A.; Calabresi, P. A.; Searson, P. C., Human iPSC-derived blood-brain barrier microvessels: validation of barrier function and endothelial cell behavior. Biomaterials 2019, 190-191, 24-37.

66. Lee, V. K.; Kim, D. Y.; Ngo, H.; Lee, Y.; Seo, L.; Yoo, S. S.; Vincent, P. A.; Dai, G., Creating perfused functional vascular channels using 3D bio-printing technology. Biomaterials 2014, 35 (28), 8092-102.

67. Tocchio, A.; Tamplenizza, M.; Martello, F.; Gerges, I.; Rossi, E.; Argentiere, S.; Rodighiero, S.; Zhao, W.; Milani, P.; Lenardi, C., Versatile fabrication of vascularizable scaffolds for large tissue engineering in bioreactor. Biomaterials 2015, 45, 124-31.

68. Contessi Negrini, N.; Bonnetier, M.; Giatsidis, G.; Orgill, D. P.; Farè, S.; Marelli, B., Tissue-mimicking gelatin scaffolds by alginate sacrificial templates for adipose tissue engineering. Acta Biomaterialia 2019, 87, 61-75.

69. Miri, A. K.; Mirzaee, I.; Hassan, S.; Mesbah Oskui, S.; Nieto, D.; Khademhosseini, A.; Zhang, Y. S., Effective bioprinting resolution in tissue model fabrication. Lab on a Chip 2019, 19 (11), 2019-2037.

70. $\quad$ Cao, X.; Ashfaq, R.; Cheng, F.; Maharjan, S.; Li, J.; Ying, G.; Hassan, S.; Xiao, H.; Yue, K.; Zhang, Y. S., A Tumor-on-a-Chip System with Bioprinted Blood and Lymphatic Vessel Pair. Advanced Functional Materials 2019, 29 (31), 1807173.

71. Grigoryan, B.; Paulsen, S. J.; Corbett, D. C.; Sazer, D. W.; Fortin, C. L.; Zaita, A. J.; Greenfield, P. T.; Calafat, N. J.; Gounley, J. P.; Ta, A. H.; Johansson, F.; Randles, A.; Rosenkrantz, J. E.; Louis-Rosenberg, J. D.; Galie, P. A.; Stevens, K. R.; Miller, J. S., Multivascular networks and functional intravascular topologies within biocompatible hydrogels. Science 2019, 364 (6439), 458.

72. Ruiz-Cantu, L.; Gleadall, A.; Faris, C.; Segal, J.; Shakesheff, K.; Yang, J., Multimaterial 3D bioprinting of porous constructs for cartilage regeneration. Materials Science and Engineering: C 2020, 109, 110578.

73. Kang, H.-W.; Lee, S. J.; Ko, I. K.; Kengla, C.; Yoo, J. J.; Atala, A., A 3D bioprinting system to produce human-scale tissue constructs with structural integrity. Nature Biotechnology 2016, 34 (3), 312-319.

74. Arumugasaamy, N.; Baker, H.; Kaplan, D.; Kim, P.; Fisher, J., Fabrication and Printing of Multi-material Hydrogels. 2016; pp 1-34.

75. Corbett, D. C.; Olszewski, E.; Stevens, K., A FRESH Take on Resolution in 3D Bioprinting. Trends Biotechnol 2019, 37 (11), 1153-1155.

76. Massa, S.; Sakr, M. A.; Seo, J.; Bandaru, P.; Arneri, A.; Bersini, S.; Zare-Eelanjegh, E.; Jalilian, E.; Cha, B. H.; Antona, S.; Enrico, A.; Gao, Y.; Hassan, S.; Acevedo, J. P.; Dokmeci, M. R.; Zhang, Y. S.; Khademhosseini, A.; Shin, S. R., Bioprinted 3D vascularized tissue model for drug toxicity analysis. Biomicrofluidics 2017, 11 (4), 044109.

77. Yanagawa, F.; Sugiura, S.; Kanamori, T., Hydrogel microfabrication technology toward three dimensional tissue engineering. Regenerative Therapy 2016, 3, 45-57.

78. Bertassoni, L. E.; Cardoso, J. C.; Manoharan, V.; Cristino, A. L.; Bhise, N. S.; Araujo, W. A.; Zorlutuna, P.; Vrana, N. E.; Ghaemmaghami, A. M.; Dokmeci, M. R.; Khademhosseini, A., Direct-write bioprinting of cell-laden methacrylated gelatin hydrogels. Biofabrication 2014, 6 (2), 024105. 
79. Blaeser, A.; Campos, D. F. D.; Puster, U.; Richtering, W.; Stevens, M. M.; Fischer, H., Controlling Shear Stress in 3D Bioprinting is a Key Factor to Balance Printing Resolution and Stem Cell Integrity. Adv Healthc Mater 2016, 5 (3), 326-333.

80. Gopinathan, J.; Noh, I., Recent trends in bioinks for 3D printing. Biomaterials Research 2018, 22 (1), 11.

81. Hospodiuk, M.; Dey, M.; Sosnoski, D.; Ozbolat, I., The bioink: A comprehensive review on bioprintable materials. Biotechnology advances 2017, 35.

82. Livoti, C. M.; Morgan, J. R., Self-assembly and tissue fusion of toroid-shaped minimal building units. Tissue Eng Part A 2010, 16 (6), 2051-61.

83. Fedorovich, N. E.; De Wijn, J. R.; Verbout, A. J.; Alblas, J.; Dhert, W. J., Threedimensional fiber deposition of cell-laden, viable, patterned constructs for bone tissue printing. Tissue Eng Part A 2008, 14 (1), 127-33.

84. Kreimendahl, F.; Köpf, M.; Thiebes, A. L.; Duarte Campos, D. F.; Blaeser, A.; Schmitz-Rode, T.; Apel, C.; Jockenhoevel, S.; Fischer, H., Three-Dimensional Printing and Angiogenesis: Tailored Agarose-Type I Collagen Blends Comprise Three-Dimensional Printability and Angiogenesis Potential for Tissue-Engineered Substitutes. Tissue Eng Part $C$ Methods 2017, 23 (10), 604-615.

85. Axpe, E.; Oyen, M. L., Applications of Alginate-Based Bioinks in 3D Bioprinting. International journal of molecular sciences 2016, 17 (12), 1976.

86. Jia, W.; Gungor-Ozkerim, P. S.; Zhang, Y. S.; Yue, K.; Zhu, K.; Liu, W.; Pi, Q.; Byambaa, B.; Dokmeci, M. R.; Shin, S. R.; Khademhosseini, A., Direct 3D bioprinting of perfusable vascular constructs using a blend bioink. Biomaterials 2016, 106, 58-68.

87. Lee, K. Y.; Mooney, D. J., Alginate: properties and biomedical applications. Prog Polym Sci 2012, 37 (1), 106-126.

88. Yu, X.; Xiao, J.; Dang, F., Surface Modification of Poly(dimethylsiloxane) Using lonic Complementary Peptides to Minimize Nonspecific Protein Adsorption. Langmuir 2015, 31 (21), 5891-5898.

89. Koh, W.-G.; Revzin, A.; Simonian, A.; Reeves, T.; Pishko, M., Control of Mammalian Cell and Bacteria Adhesion on Substrates Micropatterned with Poly(ethylene glycol) Hydrogels. Biomedical Microdevices 2003, 5 (1), 11-19.

90. Lee, H. J.; Kim, H.-S.; Kim, H. O.; Koh, W.-G., Micropatterns of double-layered nanofiber scaffolds with dual functions of cell patterning and metabolite detection. Lab on a Chip 2011, 11 (17), 2849-2857.

91. Xue, J.; Wu, T.; Dai, Y.; Xia, Y., Electrospinning and Electrospun Nanofibers: Methods, Materials, and Applications. Chemical Reviews 2019, 119 (8), 5298-5415.

92. Zhao, K.; Wang, W.; Yang, Y. Y.; Wang, K.; Yu, D. G., From Taylor cone to solid nanofiber in tri-axial electrospinning: Size relationships. Results Phys 2019, 15.

93. Khalf, A.; Madihally, S. V., Recent advances in multiaxial electrospinning for drug delivery. European Journal of Pharmaceutics and Biopharmaceutics 2017, 112, 1-17.

94. Zündel, M.; Ehret, A. E.; Mazza, E., The multiscale stiffness of electrospun substrates and aspects of their mechanical biocompatibility. Acta Biomaterialia 2019, 84, 146-158.

95. Topuz, F.; Uyar, T., Electrospinning of gelatin with tunable fiber morphology from round to flat/ribbon. Materials Science and Engineering: C 2017, 80, 371-378.

96. Bhardwaj, N.; Kundu, S. C., Electrospinning: A fascinating fiber fabrication technique. Biotechnology Advances 2010, 28 (3), 325-347.

97. Garlotta, D., A Literature Review of Poly(Lactic Acid). Journal of Polymers and the Environment 2001, 9 (2), 63-84.

98. Labet, M.; Thielemans, W., Synthesis of polycaprolactone: a review. Chemical Society Reviews 2009, 38 (12), 3484-3504.

99. Venugopal, J.; Ramakrishna, S., Applications of polymer nanofibers in biomedicine and biotechnology. Applied Biochemistry and Biotechnology 2005, 125 (3), 147-157. 
100. Yoshimoto, H.; Shin, Y. M.; Terai, H.; Vacanti, J. P., A biodegradable nanofiber scaffold by electrospinning and its potential for bone tissue engineering. Biomaterials 2003, 24 (12),

2077-2082.

101. Yan, S.; Napiwocki, B.; Xu, Y.; Zhang, J.; Zhang, X.; Wang, X.; Crone, W. C.; Li, Q.; Turng, L.-S., Wavy small-diameter vascular graft made of eggshell membrane and thermoplastic polyurethane. Materials Science and Engineering: C 2020, 107, 110311.

102. Chen, J.; Zhang, T.; Hua, W.; Li, P.; Wang, X., 3D Porous poly(lactic acid)/regenerated cellulose composite scaffolds based on electrospun nanofibers for biomineralization. Colloids and Surfaces A: Physicochemical and Engineering Aspects 2020, 585, 124048.

103. Baek, J.; Lee, E.; Lotz, M. K.; D'Lima, D. D., Bioactive proteins delivery through coreshell nanofibers for meniscal tissue regeneration. Nanomedicine: Nanotechnology, Biology and Medicine 2020, 23, 102090.

104. Kim, S.; Cha, C., Enhanced mechanical and electrical properties of heteroscaled hydrogels infused with aqueous-dispersible hybrid nanofibers. Biofabrication 2019, 12 (1), 015020.

105. Wu, L.; Gu, Y.; Liu, L.; Tang, J.; Mao, J.; Xi, K.; Jiang, Z.; Zhou, Y.; Xu, Y.; Deng, L.; Chen, L.; Cui, W., Hierarchical micro/nanofibrous membranes of sustained releasing VEGF for periosteal regeneration. Biomaterials 2020, 227, 119555.

106. Song, K. H.; Heo, S.-J.; Peredo, A. P.; Davidson, M. D.; Mauck, R. L.; Burdick, J. A., Influence of Fiber Stiffness on Meniscal Cell Migration into Dense Fibrous Networks. Advanced Healthcare Materials 2019, n/a (n/a), 1901228.

107. Roshanbinfar, K.; Vogt, L.; Ruther, F.; Roether, J. A.; Boccaccini, A. R.; Engel, F. B., Nanofibrous Composite with Tailorable Electrical and Mechanical Properties for Cardiac Tissue Engineering. Advanced Functional Materials 2020, 30 (7), 1908612.

108. Islas-Arteaga, N. C.; Raya Rivera, A.; Esquiliano Rendon, D. R.; Morales-Corona, J.; Ontiveros-Nevares, P. G.; Flores Sánchez, M. G.; Mojica-Cardoso, C.; Olayo, R., Electrospun scaffolds with surfaces modified by plasma for regeneration of articular cartilage tissue: a pilot study in rabbit. International Journal of Polymeric Materials and Polymeric Biomaterials 2019, 68 (18), 1089-1098.

109. Horner, C. B.; Maldonado, M.; Tai, Y.; Rony, R. M. I. K.; Nam, J., Spatially Regulated Multiphenotypic Differentiation of Stem Cells in 3D via Engineered Mechanical Gradient. ACS Applied Materials \& Interfaces 2019, 11 (49), 45479-45488.

110. Nagam Hanumantharao, S.; Alinezhadbalalami, N.; Kannan, S.; Friske, M.; Rao, S., Electrospun acellular scaffolds for mimicking the natural anisotropy of the extracellular matrix. RSC Advances 2019, 9 (69), 40190-40195.

111. Shambaugh, B. R.; Papavassiliou, D. V.; Shambaugh, R. L., Next-Generation Modeling of Melt Blowing. Industrial \& Engineering Chemistry Research 2011, 50 (21), 12233-12245.

112. Ginestra, P., Manufacturing of polycaprolactone - Graphene fibers for nerve tissue engineering. Journal of the Mechanical Behavior of Biomedical Materials 2019, 100, 103387.

113. Reid, J. A.; Callanan, A., Influence of aorta extracellular matrix in electrospun polycaprolactone scaffolds. Journal of Applied Polymer Science 2019, 136 (44), 48181.

114. Fujita, S.; Wakuda, Y.; Matsumura, M.; Suye, S.-i., Geometrically customizable alginate hydrogel nanofibers for cell culture platforms. Journal of Materials Chemistry B 2019, 7 (42), 6556-6563.

115. Nazari, H.; Heirani-Tabasi, A.; Hajiabbas, M.; Salimi Bani, M.; Nazari, M.; Pirhajati Mahabadi, V.; Rad, I.; Kehtari, M.; Ahmadi Tafti, S. H.; Soleimani, M., Incorporation of SPIONcasein core-shells into silk-fibroin nanofibers for cardiac tissue engineering. Journal of Cellular Biochemistry 2019, n/a (n/a).

116. Li, R.; McCarthy, A.; Zhang, Y. S.; Xie, J., Decorating 3D Printed Scaffolds with Electrospun Nanofiber Segments for Tissue Engineering. Advanced Biosystems 2019, 3 (12), 1900137. 
117. Jana, S.; Bhagia, A.; Lerman, A., Optimization of polycaprolactone fibrous scaffold for heart valve tissue engineering. Biomedical Materials 2019, 14 (6), 065014.

118. Azizi, M.; Navidbakhsh, M.; Hosseinzadeh, S.; Sajjadi, M., Cardiac cell differentiation of muscle satellite cells on aligned composite electrospun polyurethane with reduced graphene oxide. Journal of Polymer Research 2019, 26 (11), 258.

119. Abedi, A.; Hasanzadeh, M.; Tayebi, L., Conductive nanofibrous Chitosan/PEDOT:PSS tissue engineering scaffolds. Materials Chemistry and Physics 2019, 237, 121882.

120. Li, M.; Zhang, X.; Jia, W.; Wang, Q.; Liu, Y.; Wang, X.; Wang, C.; Jiang, J.; Gu, G.; Guo, Z.; Chen, Z., Improving in vitro biocompatibility on biomimetic mineralized collagen bone materials modified with hyaluronic acid oligosaccharide. Materials Science and Engineering: $C$ 2019, 104, 110008.

121. Lee, H.; Kim, W.; Lee, J.; Yoo, J. J.; Kim, G. H.; Lee, S. J., Effect of Hierarchical Scaffold Consisting of Aligned dECM Nanofibers and Poly(lactide-co-glycolide) Struts on the Orientation and Maturation of Human Muscle Progenitor Cells. ACS Applied Materials \& Interfaces 2019, 11 (43), 39449-39458.

122. Mohammadzadeh, L.; Rahbarghazi, R.; Salehi, R.; Mahkam, M., A novel egg-shell membrane based hybrid nanofibrous scaffold for cutaneous tissue engineering. Journal of biological engineering 2019, 13, 79-79.

123. Nazari, H.; Heirani-Tabasi, A.; Alavijeh, M. S.; Jeshvaghani, Z. S.; Esmaeili, E.; Hosseinzadeh, S.; Mohabatpour, F.; Taheri, B.; Tafti, S. H. A.; Soleimani, M., Nanofibrous Composites Reinforced by MoS2 Nanosheets as a Conductive Scaffold for Cardiac Tissue Engineering. ChemistrySelect 2019, 4 (39), 11557-11563.

124. Kim, D.; Eom, S.; Park, S. M.; Hong, H.; Kim, D. S., A collagen gel-coated, aligned nanofiber membrane for enhanced endothelial barrier function. Scientific reports 2019, 9 (1), $14915-14915$.

125. Chen, W.; Xu, Y.; Liu, Y.; Wang, Z.; Li, Y.; Jiang, G.; Mo, X.; Zhou, G., Threedimensional printed electrospun fiber-based scaffold for cartilage regeneration. Materials \& Design 2019, 179, 107886.

126. Hou, Y.; Wang, X.; Zhang, Z.; Luo, J.; Cai, Z.; Wang, Y.; Li, Y., Repairing Transected Peripheral Nerve Using a Biomimetic Nerve Guidance Conduit Containing Intraluminal Sponge Fillers. Advanced Healthcare Materials 2019, 8 (21), 1900913.

127. Pham, Q. P.; Sharma, U.; Mikos, A. G., Electrospun Poly( $\varepsilon$-caprolactone) Microfiber and Multilayer Nanofiber/Microfiber Scaffolds: Characterization of Scaffolds and Measurement of Cellular Infiltration. Biomacromolecules 2006, 7 (10), 2796-2805.

128. Tang, K.-C.; Yang, K.-C.; Lin, C.-W.; Chen, Y.-K.; Lu, T.-Y.; Chen, H.-Y.; Cheng, N.C.; Yu, J., Human Adipose-Derived Stem Cell Secreted Extracellular Matrix Incorporated into Electrospun Poly(Lactic-co-Glycolic Acid) Nanofibrous Dressing for Enhancing Wound Healing. Polymers 2019, 11 (10), 1609.

129. Malakpour Permlid, A.; Roci, P.; Fredlund, E.; Fält, F.; Önell, E.; Johansson, F.; Oredsson, S., Unique animal friendly $3 \mathrm{D}$ culturing of human cancer and normal cells. Toxicology in Vitro 2019, 60, 51-60.

130. Li, T.; Tian, L.; Liao, S.; Ding, X.; Irvine, S. A.; Ramakrishna, S., Fabrication, mechanical property and in vitro evaluation of poly (L-lactic acid-co- $\varepsilon$-caprolactone) core-shell nanofiber scaffold for tissue engineering. Journal of the Mechanical Behavior of Biomedical Materials 2019, 98, 48-57.

131. Sobreiro-Almeida, R.; Fonseca, D. R.; Neves, N. M., Extracellular matrix electrospun membranes for mimicking natural renal filtration barriers. Materials Science and Engineering: $C$ 2019, 103, 109866.

132. Yin, A.; Lan, X.; Zhuang, W.; Tang, Z.; Li, Y.; Wang, Y., PEGylated chitosan and PEGylated PLCL for blood vessel repair: An in vitro study. Journal of Biomaterials Applications 2019, 34 (6), 778-789. 
133. Chan, J. P.; Battiston, K. G.; Santerre, J. P., Synthesis and characterization of electrospun nanofibrous tissue engineering scaffolds generated from in situ polymerization of ionomeric polyurethane composites. Acta Biomaterialia 2019, 96, 161-174.

134. Idini, M.; Wieringa, P.; Rocchiccioli, S.; Nieddu, G.; Ucciferri, N.; Formato, M.; Lepedda, A.; Moroni, L., Glycosaminoglycan functionalization of electrospun scaffolds enhances Schwann cell activity. Acta Biomaterialia 2019, 96, 188-202.

135. Jing, X.; Li, H.; Mi, H.-Y.; Liu, Y.-J.; Tan, Y.-M., Fabrication of fluffy shish-kebab structured nanofibers by electrospinning, $\mathrm{CO} 2$ escaping foaming and controlled crystallization for biomimetic tissue engineering scaffolds. Chemical Engineering Journal 2019, 372, 785-795. 136. Sandri, G.; Rossi, S.; Bonferoni, M. C.; Miele, D.; Faccendini, A.; Del Favero, E.; Di Cola, E.; Icaro Cornaglia, A.; Boselli, C.; Luxbacher, T.; Malavasi, L.; Cantu', L.; Ferrari, F., Chitosan/glycosaminoglycan scaffolds for skin reparation. Carbohydrate Polymers 2019, 220 , 219-227.

137. Watcharajittanont, N.; Putson, C.; Pripatnanont, P.; Meesane, J., Electrospun polyurethane fibrous membranes of mimicked extracellular matrix for periodontal ligament: Molecular behavior, mechanical properties, morphology, and osseointegration. Journal of Biomaterials Applications 2019, 34 (6), 753-762.

138. Rynkevic, R.; Martins, P.; Fernandes, A.; Vange, J.; Gallego, M. R.; Wach, R. A.; Mes, T.; Bosman, A. W.; Deprest, J., In vitro simulation of in vivo degradation and cyclic loading of novel degradable electrospun meshes for prolapse repair. Polymer Testing 2019, 78, 105957. 139. Cho, H. S.; Kim, I. J.; Kim, S. C.; Park, H. C.; Kim, G. I., Harnessing the Topography of 3D Spongy-Like Electrospun Bundled Fibrous Scaffold via a Sharply Inclined Array Collector. Polymers 2019, 11 (9).

140. Wang, Y.; Guo, Z.; Qian, Y.; Zhang, Z.; Lyu, L.; Wang, Y.; Ye, F., Study on the Electrospinning of Gelatin/Pullulan Composite Nanofibers. Polymers 2019, 11 (9).

141. Elliott, C. G.; Wang, J.; Walker, J. T.; Michelsons, S.; Dunmore-Buyze, J.; Drangova, M.; Leask, A.; Hamilton, D. W., Periostin and CCN2 Scaffolds Promote the Wound Healing Response in the Skin of Diabetic Mice. Tissue Engineering Part A 2018, 25 (17-18), 1326-1339. 142. Hodge, J.; Quint, C., The improvement of cell infiltration in an electrospun scaffold with multiple synthetic biodegradable polymers using sacrificial PEO microparticles. Journal of Biomedical Materials Research Part A 2019, 107 (9), 1954-1964.

143. Jiménez Vázquez, J.; San Martín Martínez, E., Collagen and elastin scaffold by electrospinning for skin tissue engineering applications. Journal of Materials Research 2019, 34 (16), 2819-2827.

144. Yongcong, F.; Zhang, T.; Liverani, L.; Boccaccini, A. R.; Sun, W., Novel biomimetic fiber incorporated scaffolds for tissue engineering. Journal of Biomedical Materials Research Part A 2019, 107 (12), 2694-2705.

145. Ye, H.; Zhu, J.; Deng, D.; Jin, S.; Li, J.; Man, Y., Enhanced osteogenesis and angiogenesis by PCL/chitosan/Sr-doped calcium phosphate electrospun nanocomposite membrane for guided bone regeneration. Journal of Biomaterials Science, Polymer Edition 2019, 30 (16), 1505-1522.

146. Li, Y.; Xiao, Z.; Zhou, Y.; Zheng, S.; An, Y.; Huang, W.; He, H.; Yang, Y.; Li, S.; Chen, Y.; Xiao, J.; Wu, J., Controlling the Multiscale Network Structure of Fibers To Stimulate Wound Matrix Rebuilding by Fibroblast Differentiation. ACS Applied Materials \& Interfaces 2019, 11 (31), 28377-28386.

147. Sensini, A.; Cristofolini, L.; Zucchelli, A.; Focarete, M. L.; Gualandi, C.; De Mori, A.; Kao, A. P.; Roldo, M.; Blunn, G.; Tozzi, G., Hierarchical electrospun tendon-ligament bioinspired scaffolds induce changes in fibroblasts morphology under static and dynamic conditions. Journal of Microscopy 2019, n/a (n/a).

148. Davidson, M. D.; Song, K. H.; Lee, M.-H.; Llewellyn, J.; Du, Y.; Baker, B. M.; Wells, R. G.; Burdick, J. A., Engineered Fibrous Networks To Investigate the Influence of Fiber 
Mechanics on Myofibroblast Differentiation. ACS Biomaterials Science \& Engineering 2019, 5 (8), 3899-3908.

149. Reid, J. A.; Callanan, A., Hybrid cardiovascular sourced extracellular matrix scaffolds as possible platforms for vascular tissue engineering. Journal of Biomedical Materials Research Part B: Applied Biomaterials 2019, n/a (n/a).

150. Best, C. A.; Szafron, J. M.; Rocco, K. A.; Zbinden, J.; Dean, E. W.; Maxfield, M. W.; Kurobe, H.; Tara, S.; Bagi, P. S.; Udelsman, B. V.; Khosravi, R.; Yi, T.; Shinoka, T.; Humphrey, J. D.; Breuer, C. K., Differential outcomes of venous and arterial tissue engineered vascular grafts highlight the importance of coupling long-term implantation studies with computational modeling. Acta Biomaterialia 2019, 94, 183-194.

151. Azim, N.; Kundu, A.; Royse, M.; Sip, Y. Y. L.; Young, M.; Santra, S.; Zhai, L.; Rajaraman, S., Fabrication and Characterization of a 3D Printed, MicroElectrodes Platform With Functionalized Electrospun Nano-Scaffolds and Spin Coated 3D Insulation Towards MultiFunctional Biosystems. Journal of Microelectromechanical Systems 2019, 28 (4), 606-618. 152. Vardiani, M.; Gholipourmalekabadi, M.; Ghaffari Novin, M.; Koruji, M.; Ghasemi Hamidabadi, H.; Salimi, M.; Nazarian, H., Three-dimensional electrospun gelatin scaffold coseeded with embryonic stem cells and sertoli cells: A promising substrate for in vitro coculture system. Journal of Cellular Biochemistry 2019, 120 (8), 12508-12518.

153. Jia, W.; Li, M.; Kang, L.; Gu, G.; Guo, Z.; Chen, Z., Fabrication and Comprehensive Characterization of Biomimetic Extracellular Matrix Electrospun Scaffold for Vascular Tissue Engineering Applications. Journal of Materials Science 2019, 54 (15), 10871-10883.

154. Ghasemi, A.; Imani, R.; Yousefzadeh, M.; Bonakdar, S.; Solouk, A.; Fakhrzadeh, H., Studying the Potential Application of Electrospun Polyethylene Terephthalate/Graphene Oxide Nanofibers as Electroconductive Cardiac Patch. Macromolecular Materials and Engineering 2019, 304 (8), 1900187.

155. Young, R. E.; Graf, J.; Miserocchi, I.; Van Horn, R. M.; Gordon, M. B.; Anderson, C. R.; Sefcik, L. S., Optimizing the alignment of thermoresponsive poly( $\mathrm{N}$-isopropyl acrylamide) electrospun nanofibers for tissue engineering applications: A factorial design of experiments approach. PLOS ONE 2019, 14 (7), e0219254.

156. Jaganathan, S. K.; Mani, M. P.; Prabhakaran, P.; Supriyanto, E.; Ismail, A. F., Production, blood compatibility and cytotoxicity evaluation of a single stage non-woven multicomponent electrospun scaffold mixed with sesame oil, honey and propolis for skin tissue engineering. International Journal of Polymer Analysis and Characterization 2019, 24 (5), 457474.

157. Hassan, M. I.; Sultana, N., In vitro cell viability of PHBV/PLGA nanofibrous membrane for tissue engineering. Malaysian Journal of Fundamental and Applied Sciences 2019; Vol. Volume 15.

158. Augustine, R.; Hasan, A.; Patan, N. K.; Augustine, A.; Dalvi, Y. B.; Varghese, R.; Unni, R. N.; Kalarikkal, N.; Al Moustafa, A.-E.; Thomas, S., Titanium Nanorods Loaded PCL Meshes with Enhanced Blood Vessel Formation and Cell Migration for Wound Dressing Applications. Macromolecular Bioscience 2019, 19 (7), 1900058.

159. Liu, C.; Li, B.; Mao, X.; Zhang, Q.; Sun, R.; Gong, R. H.; Zhou, F., Controllable Aligned Nanofiber Hybrid Yarns with Enhanced Bioproperties for Tissue Engineering.

Macromolecular Materials and Engineering 2019, 304 (7), 1900089.

160. Li, Z.; Lei, I. M.; Davoodi, P.; Huleihel, L.; Huang, Y. Y. S., Solution Formulation and Rheology for Fabricating Extracellular Matrix-Derived Fibers Using Low-Voltage Electrospinning Patterning. ACS Biomaterials Science \& Engineering 2019, 5 (7), 3676-3684.

161. Zhijiang, C.; Ping, X.; Shiqi, H.; Cong, Z., Soy protein nanoparticles modified bacterial cellulose electrospun nanofiber membrane scaffold by ultrasound-induced self-assembly technique: characterization and cytocompatibility. Cellulose 2019, 26 (10), 6133-6150. 
162. Sadeghi, A.; Zandi, M.; Pezeshki-Modaress, M.; Rajabi, S., Tough, hybrid chondroitin sulfate nanofibers as a promising scaffold for skin tissue engineering. International Journal of Biological Macromolecules 2019, 132, 63-75.

163. Simbara, M. M. O.; Santos Jr, A. R.; Andrade, A. J. P.; Malmonge, S. M., Comparative study of aligned and nonaligned poly( $\varepsilon$-caprolactone) fibrous scaffolds prepared by solution blow spinning. Journal of Biomedical Materials Research Part B: Applied Biomaterials 2019, 107 (5), 1462-1470.

164. Lima, L. L.; Taketa, T. B.; Beppu, M. M.; Sousa, I. M. d. O.; Foglio, M. A.; Moraes, Â. M., Coated electrospun bioactive wound dressings: Mechanical properties and ability to control lesion microenvironment. Materials Science and Engineering: C 2019, 100, 493-504.

165. Du, H.; Tao, L.; Wang, W.; Liu, D.; Zhang, Q.; Sun, P.; Yang, S.; He, C., Enhanced biocompatibility of poly(I-lactide-co-epsilon-caprolactone) electrospun vascular grafts via selfassembly modification. Materials Science and Engineering: C 2019, 100, 845-854.

166. Atrian, M.; Kharaziha, M.; Emadi, R.; Alihosseini, F., Silk-Laponite® fibrous membranes for bone tissue engineering. Applied Clay Science 2019, 174, 90-99.

167. Luan, X.; Wang, H.; Xiang, Z.; Ma, Z.; Zhao, J.; Feng, Y.; Shi, Q.; Yin, J., Biomimicking Dual-Responsive Extracellular Matrix Restoring Extracellular Balance through the $\mathrm{Na} / \mathrm{K}-A T P a s e$ Pathway. ACS Applied Materials \& Interfaces 2019, 11 (23), 21258-21267. 168. Jing, X.; Li, H.; Mi, H.-Y.; Liu, Y.-J.; Tan, Y.-M., Fabrication of Three-Dimensional Fluffy Nanofibrous Scaffolds for Tissue Engineering via Electrospinning and CO2 Escaping Foaming. Industrial \& Engineering Chemistry Research 2019, 58 (22), 9412-9421. 169. Gill, E. L.; Willis, S.; Gerigk, M.; Cohen, P.; Zhang, D.; Li, X.; Huang, Y. Y. S., Fabrication of Designable and Suspended Microfibers via Low-Voltage 3D Micropatterning. ACS Applied Materials \& Interfaces 2019, 11 (22), 19679-19690.

170. Youssef, A.; Hrynevich, A.; Fladeland, L.; Balles, A.; Groll, J.; Dalton, P. D.; Zabler, S., The Impact of Melt Electrowritten Scaffold Design on Porosity Determined by X-Ray Microtomography. Tissue Engineering Part C: Methods 2019, 25 (6), 367-379.

171. Aghaei-Ghareh-Bolagh, B.; Mithieux, S. M.; Hiob, M. A.; Wang, Y.; Chong, A.; Weiss, A. S., Fabricated tropoelastin-silk yarns and woven textiles for diverse tissue engineering applications. Acta Biomaterialia 2019, 91, 112-122.

172. Fallahi, A.; Mandla, S.; Kerr-Phillip, T.; Seo, J.; Rodrigues, R. O.; Jodat, Y. A.; Samanipour, R.; Hussain, M. A.; Lee, C. K.; Bae, H.; Khademhosseini, A.; Travas-Sejdic, J.; Shin, S. R., Flexible and Stretchable PEDOT-Embedded Hybrid Substrates for Bioengineering and Sensory Applications. ChemNanoMat 2019, 5 (6), 729-737.

173. Beishenaliev, A.; Lim, S. S.; Tshai, K. Y.; Khiew, P. S.; Moh'd Sghayyar, H. N.; Loh, $\mathrm{H}$.-S., Fabrication and preliminary in vitro evaluation of ultraviolet-crosslinked electrospun fish scale gelatin nanofibrous scaffolds. Journal of Materials Science: Materials in Medicine 2019, 30 (6), 62.

174. Du, J.; Wang, J.-H.; Yu, H.-Y.; Zhang, Y.-Y.; Pu, L.-H.; Wang, J.-C.; Lu, S.-Y.; Chen, S.-H.; Zhu, T.-H., Electrospun Poly(p-dioxanone)/Poly(ester-urethane)ureas Composite Nanofibers for Potential Heart Valve Tissue Reconstruction. Chinese Journal of Polymer Science 2019, 37 (6), 560-569.

175. Xie, X.; Li, D.; Su, C.; Cong, W.; Mo, X.; Hou, G.; Wang, C., Functionalized Biomimetic Composite Nanfibrous Scaffolds with Antibacterial and Hemostatic Efficacy for Facilitating Wound Healing. Journal of Biomedical Nanotechnology 2019, 15 (6), 1267-1279. 176. Gluais, M.; Clouet, J.; Fusellier, M.; Decante, C.; Moraru, C.; Dutilleul, M.; Veziers, J.; Lesoeur, J.; Dumas, D.; Abadie, J.; Hamel, A.; Bord, E.; Chew, S. Y.; Guicheux, J.; Le Visage, C., In vitro and in vivo evaluation of an electrospun-aligned microfibrous implant for Annulus fibrosus repair. Biomaterials 2019, 205, 81-93.

177. Carvalho, M. S.; Silva, J. C.; Udangawa, R. N.; Cabral, J. M. S.; Ferreira, F. C.; da Silva, C. L.; Linhardt, R. J.; Vashishth, D., Co-culture cell-derived extracellular matrix loaded 
electrospun microfibrous scaffolds for bone tissue engineering. Materials Science and Engineering: C 2019, 99, 479-490.

178. Dias, F. T. G.; Ingracio, A. R.; Nicoletti, N. F.; Menezes, F. C.; Dall Agnol, L.; Marinowic, D. R.; Soares, R. M. D.; da Costa, J. C.; Falavigna, A.; Bianchi, O., Soybeanmodified polyamide- 6 mats as a long-term cutaneous wound covering. Materials Science and Engineering: C 2019, 99, 957-968.

179. Liu, S.; Niu, C.; Xu, Z.; Wang, Y.; Liang, Y.; Zhao, Y.; Zhao, Y.; Yang, Y., Modulation of myelin formation by combined high affinity with extracellular matrix structure of electrospun silk fibroin nanoscaffolds. Journal of Biomaterials Science, Polymer Edition 2019, 30 (12), 10681082.

180. Li, G.; Li, P.; Chen, Q.; Mani, M. P.; Jaganathan, S. K., Enhanced mechanical, thermal and biocompatible nature of dual component electrospun nanocomposite for bone tissue engineering. PeerJ 2019, 7, e6986.

181. Polonio-Alcalá, E.; Rabionet, M.; Gallardo, X.; Angelats, D.; Ciurana, J.; RuizMartínez, S.; Puig, T., PLA Electrospun Scaffolds for Three-Dimensional Triple-Negative Breast Cancer Cell Culture. Polymers 2019, 11 (5).

182. Fernández, J.; Ruiz-Ruiz, M.; Sarasua, J.-R., Electrospun Fibers of Polyester, with Both Nano- and Micron Diameters, Loaded with Antioxidant for Application as Wound Dressing or Tissue Engineered Scaffolds. ACS Applied Polymer Materials 2019, 1 (5), 1096-1106.

183. Menezes, R.; Hashemi, S.; Vincent, R.; Collins, G.; Meyer, J.; Foston, M.; Arinzeh, T. $\mathrm{L}$., Investigation of glycosaminoglycan mimetic scaffolds for neurite growth. Acta Biomaterialia 2019, 90, 169-178.

184. Altun, E.; Aydogdu, M. O.; Togay, S. O.; Sengil, A. Z.; Ekren, N.; Haskoylu, M. E.; Oner, E. T.; Altuncu, N. A.; Ozturk, G.; Crabbe-Mann, M.; Ahmed, J.; Gunduz, O.; Edirisinghe, M., Bioinspired scaffold induced regeneration of neural tissue. European Polymer Journal 2019, 114, 98-108.

185. Smoak, M. M.; Han, A.; Watson, E.; Kishan, A.; Grande-Allen, K. J.; CosgriffHernandez, E.; Mikos, A. G., Fabrication and Characterization of Electrospun Decellularized Muscle-Derived Scaffolds. Tissue Engineering Part C: Methods 2019, 25 (5), 276-287. 186. Yu, T.; Gleeson, S. E.; Li, C. Y.; Marcolongo, M., Electrospun poly( $(\varepsilon$-caprolactone) nanofiber shish kebabs mimic mineralized bony surface features. Journal of Biomedical Materials Research Part B: Applied Biomaterials 2019, 107 (4), 1141-1149.

187. Patel, K. H.; Dunn, A. J.; Talovic, M.; Haas, G. J.; Marcinczyk, M.; Elmashhady, H.; Kalaf, E. G.; Sell, S. A.; Garg, K., Aligned nanofibers of decellularized muscle ECM support myogenic activity in primary satellite cells in vitro. Biomedical Materials 2019, 14 (3), 035010. 188. Zhong, L.; Hu, D.; Qu, Y.; Peng, J.; Huang, K.; Lei, M.; Wu, T.; Xiao, Y.; Gu, Y.; Qian, Z., Preparation of Adenosine-Loaded Electrospun Nanofibers and Their Application in Bone Regeneration. Journal of Biomedical Nanotechnology 2019, 15 (5), 857-877.

189. Mirzaei, A.; Saburi, E.; Islami, M.; Ardeshirylajimi, A.; Omrani, M. D.; Taheri, M.; Moghadam, A. S.; Ghafouri-Fard, S., Bladder smooth muscle cell differentiation of the human induced pluripotent stem cells on electrospun Poly(lactide-co-glycolide) nanofibrous structure. Gene 2019, 694, 26-32.

190. Grant, R.; Hallett, J.; Forbes, S.; Hay, D.; Callanan, A., Blended electrospinning with human liver extracellular matrix for engineering new hepatic microenvironments. Scientific reports 2019, 9 (1), 6293-6293.

191. Kumar, D.; Cain, S. A.; Bosworth, L. A., Effect of Topography and Physical Stimulus on hMSC Phenotype Using a 3D In Vitro Model. Nanomaterials (Basel, Switzerland) 2019, 9 (4), 522.

192. Chen, C.; Townsend, A. D.; Sell, S. A.; Martin, R. S., Microchip-based 3D-cell culture using polymer nanofibers generated by solution blow spinning. Analytical Methods 2017, 9 (22), 3274-3283. 
193. Vashaghian, M.; Zaat, S. J.; Smit, T. H.; Roovers, J.-P., Biomimetic implants for pelvic floor repair. Neurourology and Urodynamics 2018, 37 (2), 566-580.

194. Terranova, L.; Dragusin, D. M.; Mallet, R.; Vasile, E.; Stancu, I.-C.; Behets, C.; Chappard, D., Repair of calvarial bone defects in mice using electrospun polystyrene scaffolds combined with $\beta$-TCP or gold nanoparticles. Micron 2017, 93, 29-37.

195. Leong, M. F.; Lu, H. F.; Lim, T. C.; Du, C.; Ma, N. K. L.; Wan, A. C. A., Electrospun polystyrene scaffolds as a synthetic substrate for xeno-free expansion and differentiation of human induced pluripotent stem cells. Acta Biomaterialia 2016, 46, 266-277.

196. Barrientos, I. J. H.; MacKenzie, G. R.; Wilson, C. G.; Lamprou, D. A.; Coats, P., Biological Performance of Electrospun Polymer Fibres. Materials 2019, 12 (3).

197. Farokhi, M.; Mottaghitalab, F.; Fatahi, Y.; Khademhosseini, A.; Kaplan, D. L., Overview of Silk Fibroin Use in Wound Dressings. Trends Biotechnol 2018, 36 (9), 907-922.

198. Rockwood, D. N.; Preda, R. C.; Yucel, T.; Wang, X. Q.; Lovett, M. L.; Kaplan, D. L., Materials fabrication from Bombyx mori silk fibroin. Nat Protoc 2011, 6 (10), 1612-1631.

199. Kishan, A. P.; Cosgriff-Hernandez, E. M., Recent advancements in electrospinning design for tissue engineering applications: A review. J Biomed Mater Res A 2017, 105 (10), 2892-2905.

200. Pimentel, E. S.; Brito-Pereira, R.; Marques-Almeida, T.; Ribeiro, C.; Vaz, F.;

Lanceros-Mendez, S.; Cardoso, V. F., Tailoring Electrospun Poly(L-lactic acid) Nanofibers as Substrates for Microfluidic Applications. Acs Appl Mater Inter 2020, 12 (1), 60-69.

201. Chen, C.; Mehl, B. T.; Sell, S. A.; Martin, R. S., Use of electrospinning and dynamic air focusing to create three-dimensional cell culture scaffolds in microfluidic devices. The Analyst 2016, 141 (18), 5311-5320.

202. Chen, C. P.; Townsend, A. D.; Hayter, E. A.; Birk, H. M.; Sell, S. A.; Martin, R. S., Insert-based microfluidics for 3D cell culture with analysis. Anal Bioanal Chem 2018, 410 (12), 3025-3035.

203. Chen, C.; Townsend, A. D.; Hayter, E. A.; Birk, H. M.; Sell, S. A.; Martin, R. S., Insertbased microfluidics for 3D cell culture with analysis. Analytical and bioanalytical chemistry 2018, 410 (12), 3025-3035. 